\title{
Simulation of Switched Reluctance Machine with 'E' Model Stator Based on Ansoft
}

\author{
Ma Xiaojun ${ }^{1}$, Tan Junyang ${ }^{1, a}$, liu Chunguang ${ }^{1}$, Wang Guodong ${ }^{1}$ \\ ${ }^{1} 21$ Court, Dujiakan, Fengtai District, Beijing, P.R. of China \\ am13121574596@163.com
}

Keywords: Switched Reluctance Machine, Modularization, Ansoft Maxwell

\begin{abstract}
The switched reluctance machine with a modularized stator is introduced for its theory. Then, the switched reluctance machine is finite element analyzed by the use of Ansoft Maxwell to simulate its performance.
\end{abstract}

The switched reluctance motor, which is called SR motor, has a few advantages such as simple construction, low cost, solid organism and wide speed regulation. This kind of motor is also used in industrial and agriculture. This paper introduced a new kind of switched reluctance motor with a modularized stator, and simulated this ' $E$ ' modularized, 3 phases and 6/4 poles motor in finite element analysis.

\section{Structure of the modularized stator SRM}

SR motor's working principle will obey the 'minimum reluctance principle', which means the flux will close in the minimum reluctance road. In order to move the rotor core to the minimum reluctance position, the principal axis must coincide with the magnetic axis. If the phase is charged with electricity in order, the rotor will rotate in opposite order. It means that the rotating direction of SR motor is decided by the current order of all the phases.

\section{Introduction of ' $E$ ' modularized stator SRM}

The 'E' modularized stator SRM has two kinds, double package SRM and single package SRM, due to its winding method. The structure of double package SRM is shown in Fig. 1 as fellow.

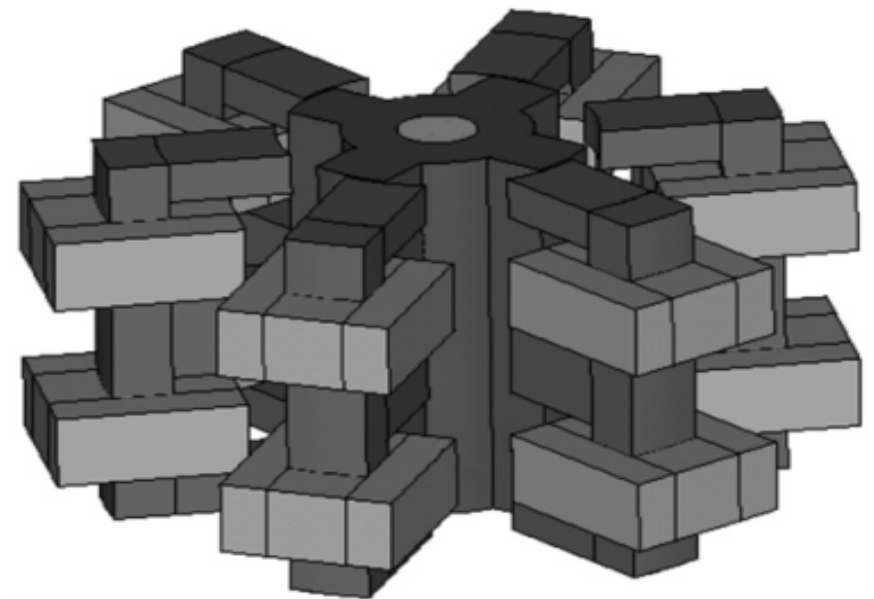

Fig.1 Structure of double package SRM

The 'E' modularized stator SRM has some advantages as fellow.

The stator winding is in the iron core of stator. The winding space is so big that the motor's magnetic motive force will be increased.

Every stator has its own winding so that the performance of motor can be ensured.

The iron core became smaller, and the stator iron has been modularized. Hence, it gets a lower cost.

The stator winding is much more flexible. The motor gets smaller. 
The stator iron core looks like a letter ' $E$ '. The main flux which cross the gap between stator iron core and the rotor iron core to deliver a force for the rotor. It becomes much more effective.

\section{The magnetic analysis based on Ansoft Maxwell}

The motor's model is established in Ansoft Maxwell based on the 6/4 poles double package ' $E$ ' SRM. And the model is simulated and analyzed. The model is shown in Fig.2 as fellow.

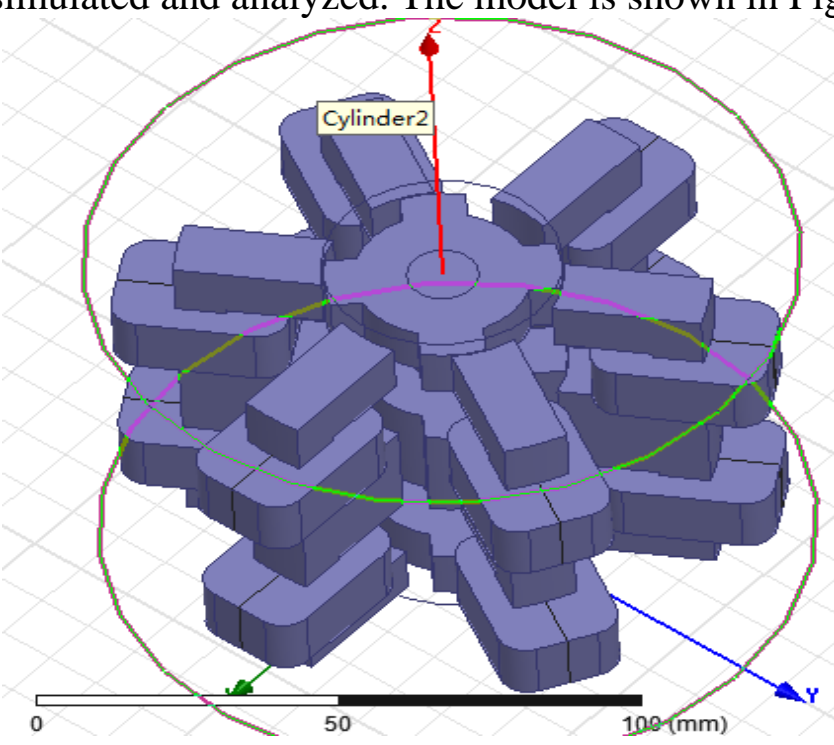

Fig. 2 6/4 poles double package 'E' modularized stator SRM

The controlling circuit drawn in Maxwell Circuit Editor is shown in Fig.3 as fellow.

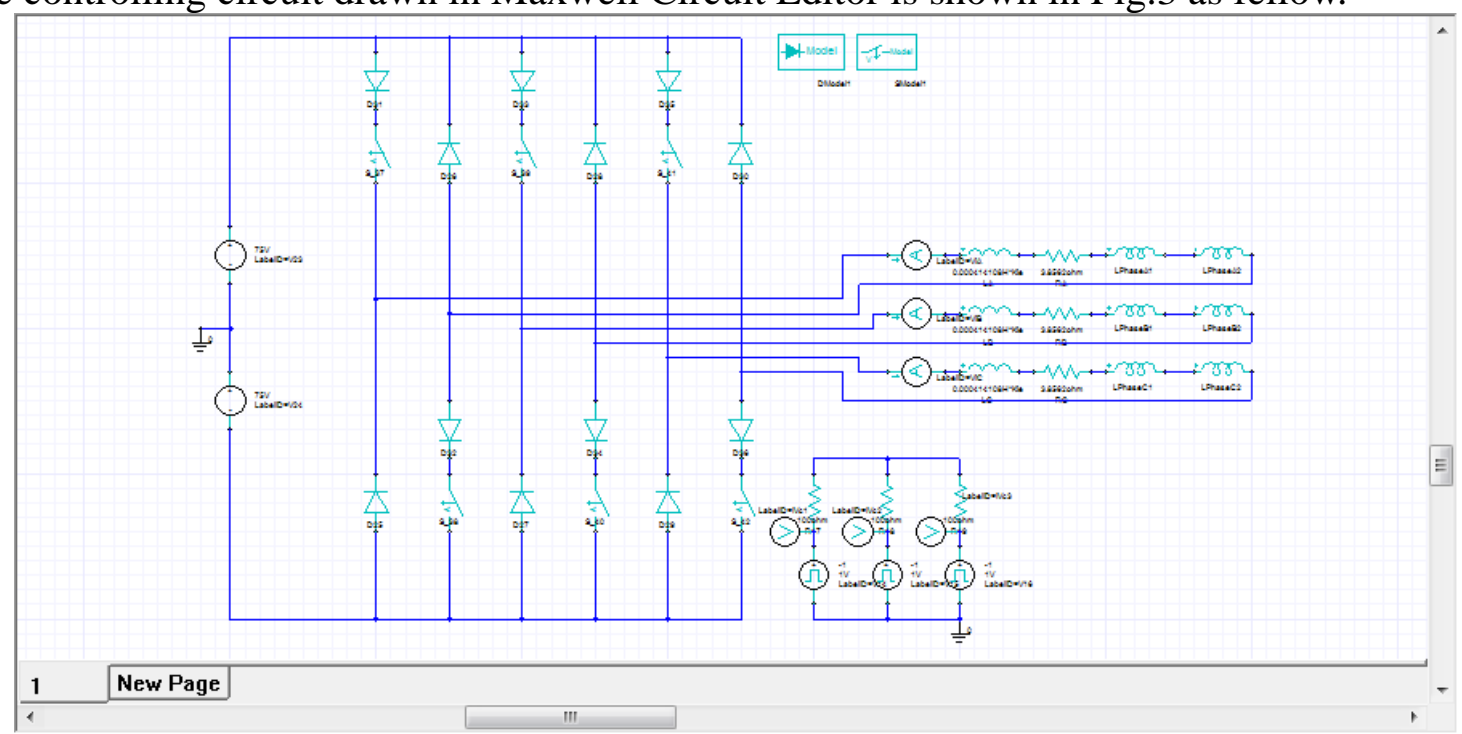

Fig.3 The controlling circuit of switched reluctance machine

It can be drawn that the torque gets bigger with the increasingly rotate angular. And it reduces to 0 after reached the peak. It is said that the changeable value of the rotor's position is fit in the minimum reluctance principle of switched reluctance machine. Meanwhile, the value of torque is related to the value of current in the winding. They performed in a direct proportion. The Fig. 4 shows that the curve between 45 degree and 90 degree is symmetrical with the curve between 0 degree and 45 degree. The value of flux linkage is also in a direct proportion with the value of current in winding. And the value of flux linkage is change with the rotor's position. 


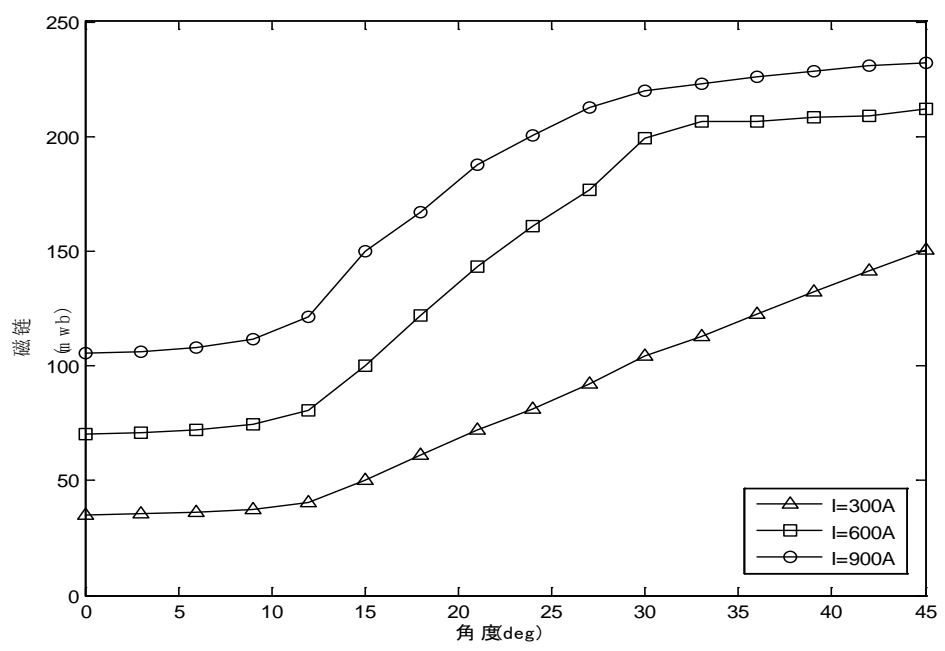

Fig.4 The curve of flux linkage change with rotor

The immediate simulation of the motor is taken under the rated condition. And the simulated conclusions are shown in Fig. 5 as fellow.

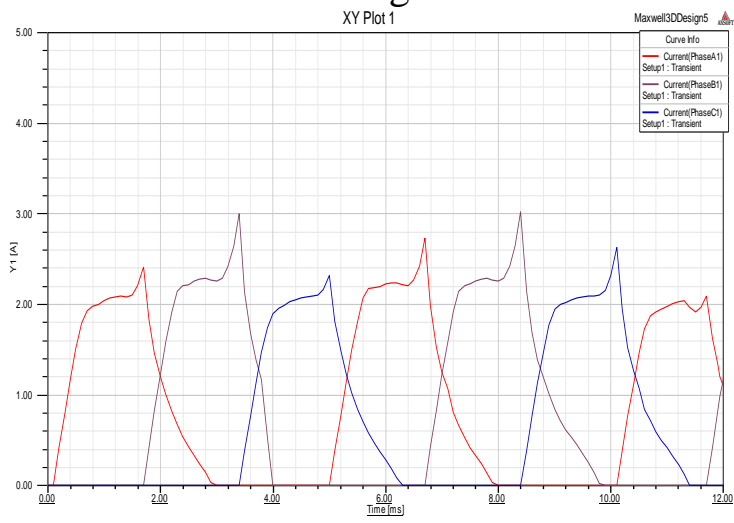

(a)Current-Time under rated condition

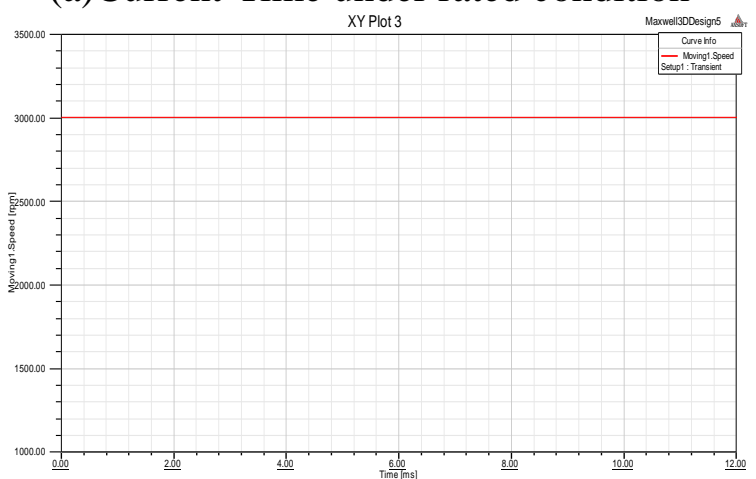

(c)Rotate speed-Time under rated condition

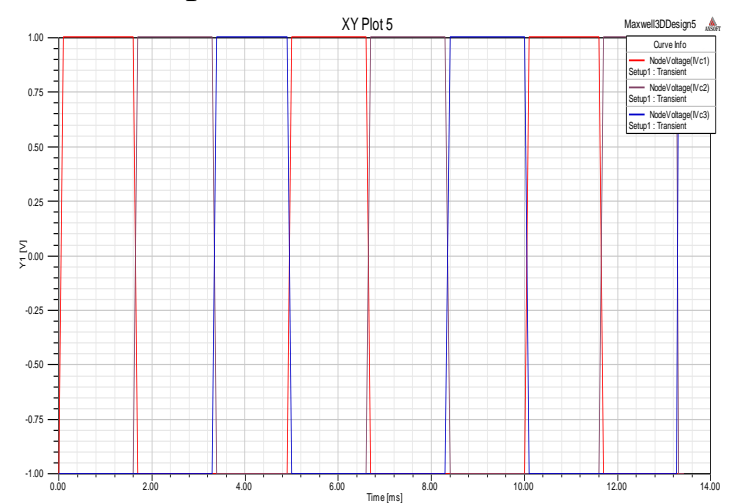

(e)Voltage-Time under rated condition

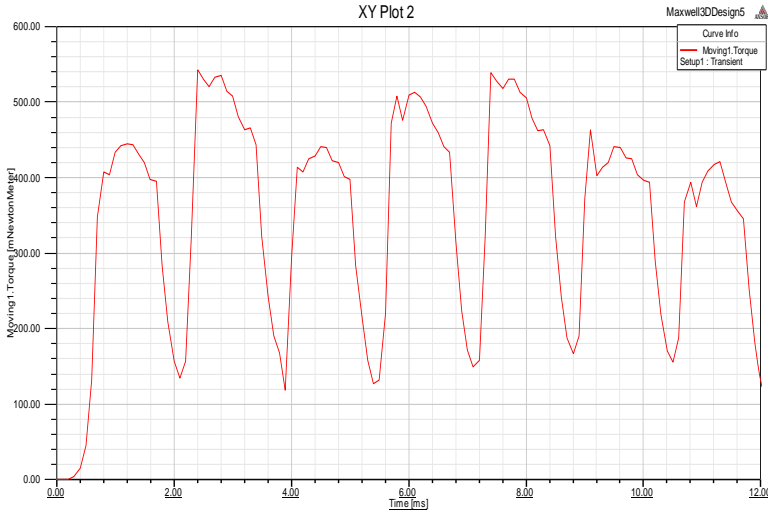

(b)Torque-Time under rated condition

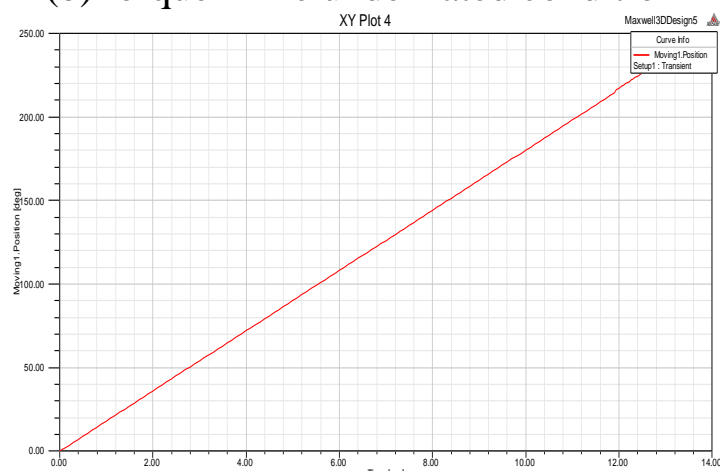

(d)Angular-Time under rated condition

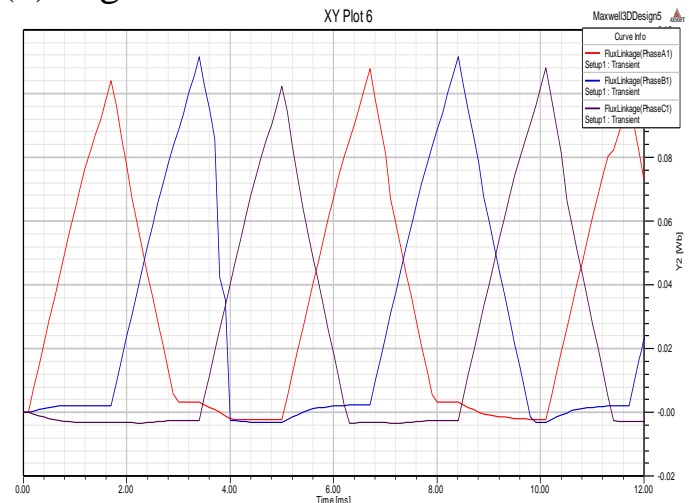

(f)Flux linkage-Time under rated condition

Fig.5 The conclusion of simulation 
The motor works in a good condition when the rotate speed gets its rated speed. Meanwhile, the rotor angular changes linearly. A, B, C phase break over in order to shape a pulse torque, which is also the biggest characteristic of switched reluctance machine. After all, the value of torque should be paid more attention when design a switched reluctance machine.

\section{Conclusion}

The 3 phases 6/4 poles double package ' $E$ ' modularized stator SRM is simulated. It is found that the value of torque is in a direct proportion with the value of current.

The switched reluctance machine is simulated in immediate magnetic field. It is found that the machine works in a good condition under the rated condition. And the current of 3 phases break over in order to rotate the machine's rotor.

\section{References}

[1] YAN Zhi-an, CUI Xin-yi, SUI Shao-ping. Electromechanics[M]. 2006.

[2] WU Jian-hua. Design and application of switched reluctance motor[M]. 2000.

[3] Shang-Hsun Mao, Mi-Ching Tsai,A novel SRM with C-core stators[J],National Cheng Kung University.2005.

[4] WU Hong-xing ,NI Tian. Summarize of new type switched reluctance motor development[J].Micro-machine.2011.

[5] ZHAO Bo. Application of Ansoft12 in electromagnetic field of engineering[M].2010.

[6] Majid Hajatipour, Mohammad Farrokhi. Adaptive intelligent speed control of switched reluctance motors with torque ripple reduction[J].Energy Conversion and Management,49:1028-1038,2008. 